\title{
DIFFERENTIAL HYDR0-MECHANICAL TRANSMISSIONS WITH HYDROSTATIC UNITS
}

At present, hydromechanical transmissions are used especially in agricultural and defence vehicles. These transmissions have potential to be used also in other vehicles, for example commercial cars and buses. Differential hydromechanical transmission generation needs to achieve comparable parameters in comparison with the competition to prove maximum of drive comfort, safety, reliability and efficiency.

Keywords: transmission, power split, epicyclical gears, hydrostatic unit, continuously variable transmission - CVT, drive comfort, safety

\section{Introduction}

Vehicle producers and transmission developers use the principles of continuously variable transmission without power flow break. The most known producers developed differential transmissions with hydrostatic units placed in parallel power flow branch. Agricultural tractors, defence vehicles and special crawlers are equipped with this type of transmission. The new innovative solutions are listed below.

\section{Deutz-fahr Agrotron}

The demands to a modern infinitely variable transmission are clear - high tractive force with low hydrostatic involvement, low maintenance costs and user convenience. The Agrotron TTV transmission, developed in DEUTZ-FAHR and ZF collaboration, has entered new dimensions in stepless transmission technology: Practical operating convenience, high efficiency and exemplary economy are the main characteristics of this transmission.

High mechanical efficiency

A hitherto unsurpassed efficiency for a stepless transmission is possible due to the use of state-of-the-art technology. In each of the four working ranges the maximum driving power is mechanically transferred. The hydrostatic share is reduced to a minimum, ensuring maximum efficiency without hydraulic losses, at lower speeds during fieldwork.

\section{Intelligent transmission design}

The stepless, performance-graded transmission of the Agrotron TTV comprises four main components - planetary transmission, the hydrostatic unit, the shuttle clutches and the electronic control unit. The high degree of efficiency is ensured due to the direct power flow from engine to the, planetary transmission, shuttle transmission, PTO and axle.

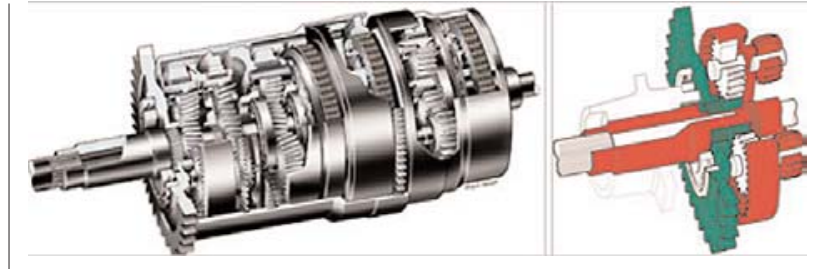

Fig. 1: Agrotron TTV gearbox cross section and detail of the power split point

Variability from 0 to $50 \mathrm{~km} / \mathrm{h}$

The transmission comprises four planetary trains. The entire speed range is practically divided into the four working ranges by the planetary trains. The speed is steplessly varied within each working range by a hydrostatic unit. This gives you the possibility of infinitely variable travel speeds from $0-50 \mathrm{~km} \cdot \mathrm{h}^{-1}$, using the combination of the planetary trains and the hydrostatic unit. The planetary trains are inter-connected by maintenance-free long life multi-plate clutches.

\section{Coordination}

The hydrostatic variable displacement pump is directly driven, via the main shaft, from the engine. The variable displacement pump determines the oil flow rate and therefore, the speed of the

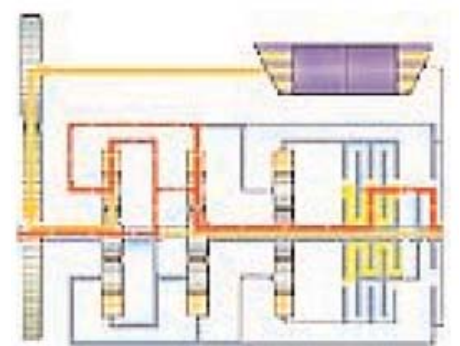

Fig. 2: Power flow through Agrotron TTV gearbox

\footnotetext{
* František Brumerčík, Roman Kocúr, Milan Pažičan, Michal Lukáč

Department of Design and Machine Elements, Faculty of Mechanical Engineering, University of Zilina, Slovakia

E-mail: frantisek.brumercik@fstroj.utc.sk,roman.kocur@fstroj.utc.sk,milan.pazican@fstroj.utc.sk, michal.lukac@fstroj.utc.sk
} 


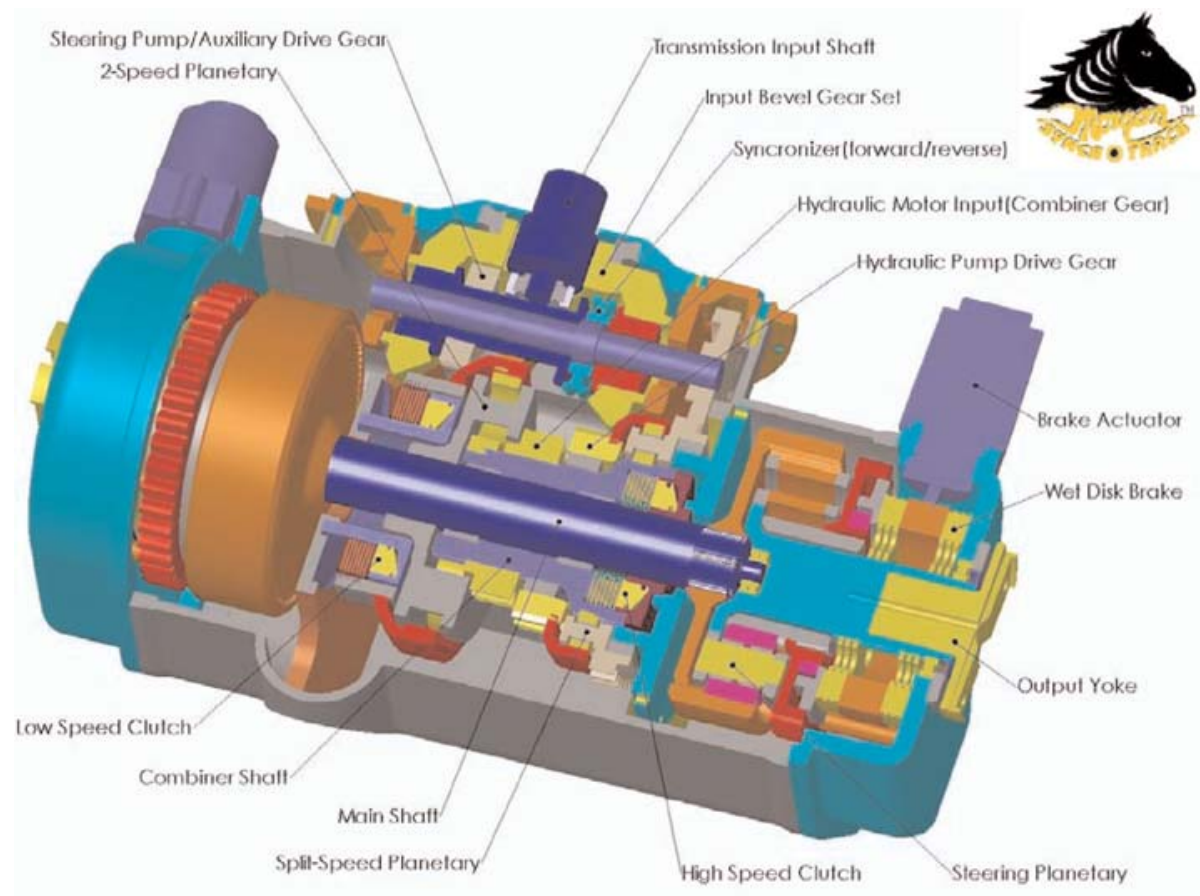

Fig. 3: Silvatech CVT cross section

fixed output motor. The less oil pumped the lower the speed of the fixed output motor and therefore the lower the hydrostatic power share.

\section{Silvatech defence}

Silvatech Continuously Variable Transmission was developed especially for defence vehicles, but it can be used also in other applications.

\section{Applications and features}

Silvatech CVT can be used in vocational trucks, cement mixers, refuse trucks, agriculture, defence, forestry, mining, buses, construction. It provides:

- faster acceleration

- reliable on board diagnostics

- driving without shifting means greater working comfort and valuable contribution to safety

- low heat load

- the vehicle could be stopped without operating the brake, even on slopes or inclines

- reduced emissions

- each speed is continuously variable

- automatic operation with heavy loads in the optimum power zone is easily possible

- the ideal operating condition of the entire system is automatically assured for every situation

The compact design and advanced drive system is ideal for military applications.
SILVATECH'S power pack offers a user features that allows for optimum performance resulting in improved vehicle mobility with smoother, immediate, and more efficient vehicle response.

Silvatech has been producing reliable, rugged mobile application drive systems with $80 \%$ less moving parts than conventional drive trains for the past decade. Any operational trouble, should it arise, is quickly diagnosed and repaired, by local technicians, usually in the field.

\section{Torvec-IVT}

Torvec's breakthrough Infinitely Variable Transmission (IVT ${ }^{\mathrm{TM}}$ ) combines the Company's innovative and patented hydraulic pump technology with patented gearing and valving resulting in a technological marvel. The transmission reaches efficiencies in ranges where others aren't even measured, and also cuts down on noxious emissions.

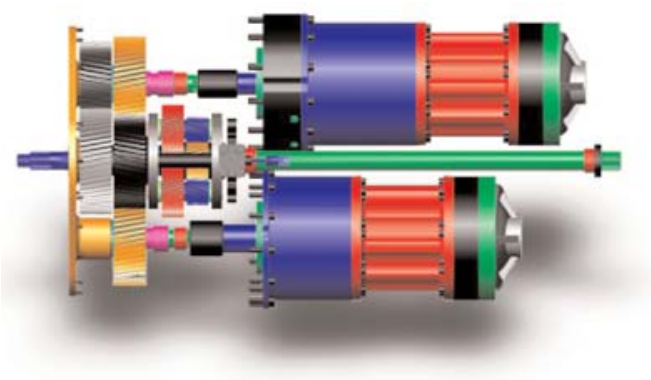

Fig. 5: Torvec-IVT scheme 


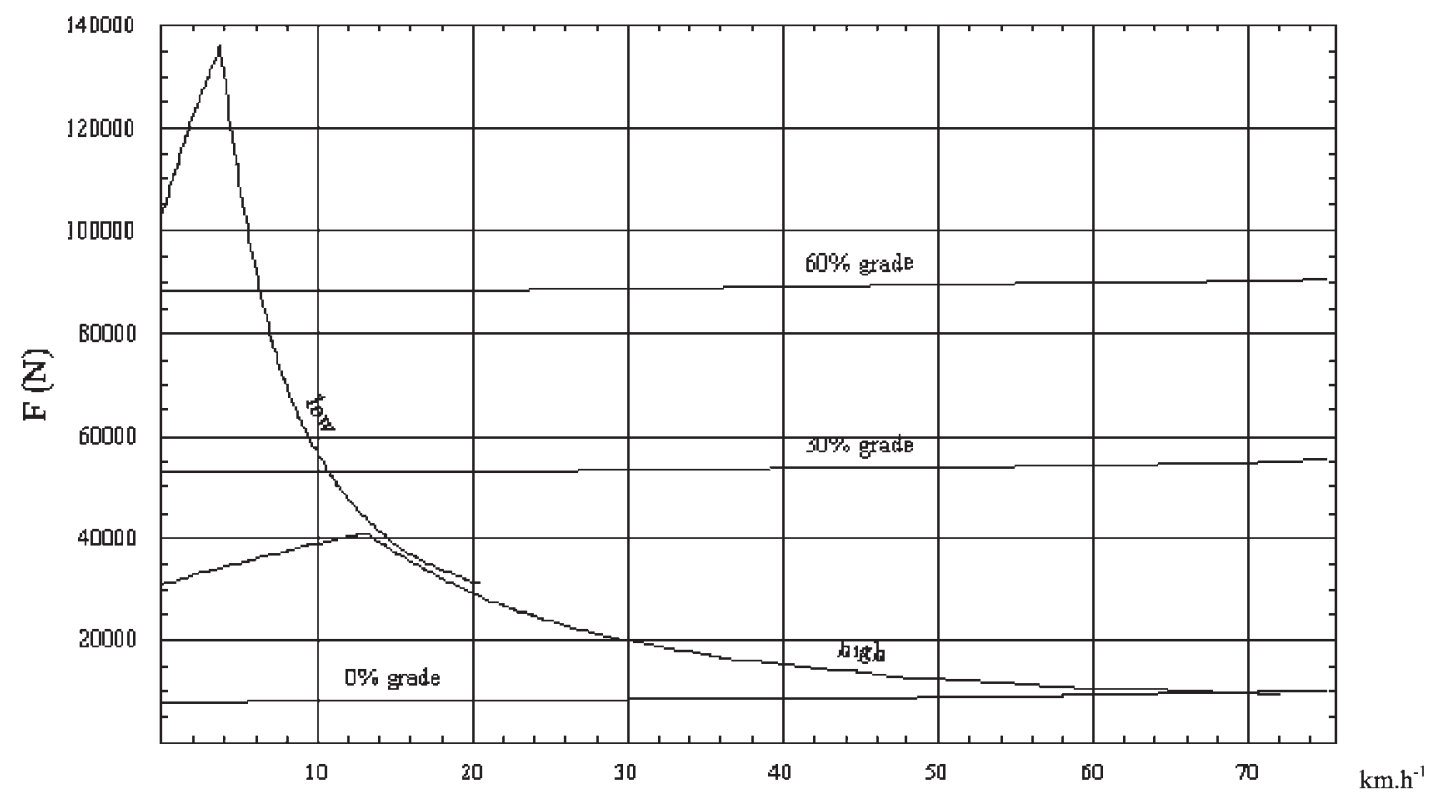

Fig.. 4: Performance diagram of vehicle equipped with Silvatech CVT

The configuration shown here is designed for high-torque diesel applications. The Torvec IVT ${ }^{\mathrm{TM}}$ design was an offshoot of our already proven tracked vehicle steering mechanism. The transmission can bolt into existing drive trains with no redesign of the automobile. There is no economic penalty in choosing the IVT'M to replace existing automotive transmissions.

The IVT'M is designed for reliability and durability. There are over $70 \%$ fewer parts to fail, all key wear parts operate in hydraulic fluid containment, and there is minimal metal on metal contact. Safety is also inherent in the design. The IVT ${ }^{\mathrm{TM}}$ is equally as safe as a conventional transmission, there are very few functions to control and the transmission eliminates vehicle creep (forward movement) at idle while in Drive.

Based upon these results and automotive industry requests, Torvec is currently installing an even less expensive version of the IVT ${ }^{\mathrm{TM}}$ using only its patented pump and motor, in a gasoline powered GM Tahoe SUV. Torvec believes that this installation will demonstrate that its IVT ${ }^{\mathrm{TM}}$ technology is commercially ready for production and utilization in the full spectrum of gasoline and diesel powered vehicles.
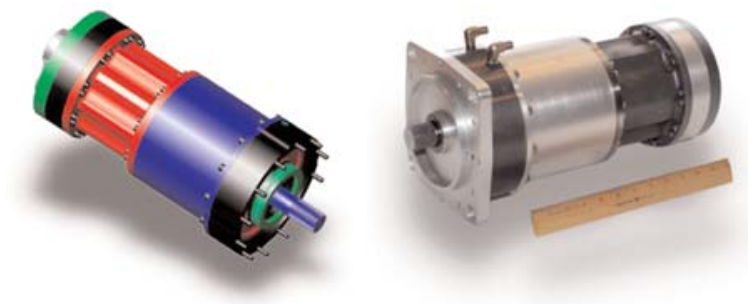

Fig. 6: Torvec's $200 \mathrm{~cm}^{3}$ displacement pump - CAD model and a prototype

\section{Hydraulic pump / motor}

Torvec has redefined the science of hydraulics. The result is the Torvec Hydraulic Pump and Motor - the major breakthrough behind the IVT ${ }^{\mathrm{TM}}$.

These pumps and motors have a place of their own in the industrial pump market. Current hydraulics suffer from critical problems:

- Rotating piston group

- Inefficient valving

- Hydraulic whine

- Heavy housings

Existing pumps need to be large and heavy in order to deliver the desired power. The size and weight prove detrimental in automotive design, as valuable space and weight are eaten up by the hardware.

Torvec innovation led to the design of their own Hydraulic Pump. Torvec has eliminated the rotating piston group (the cylinders are stationary), making the pump tremendously powerful and easy to manufacture.Torvec's patented valving has been integrated to increase efficiency and reduce noise (hydraulic whine).

The challenge was to deliver the necessary power while reducing the size and weight of the pump, using parts that can be manufactured at high volume and low cost. The design solution resulted in a pump with extremely high power density (horsepower to weight ratio), at less than half of the industry standard weight for a comparable hydraulic pump. For example, most $200 \mathrm{~cm}^{3}$ displacement pumps range from $90.7-122.5 \mathrm{~kg}$, while Torvec's displacement pump weighs approximately $34 \mathrm{~kg}$. 


\section{Steyr CVT}

\section{Hydrostatic unit}

A hydrostatic fixed displacement motor, which is directly pressurised with the oil flow conveyed by the pump, is mounted back to back onto a variable hydrostatic pump. Through electrohydraulic adjustment of the inclined plate $\left(55 \mathrm{~cm}^{3}\right.$ capacity, 430 bar maximum pressure) in the hydrostatic pump both the speed as well as the rotational direction of the hydrostatic motor can be changed.

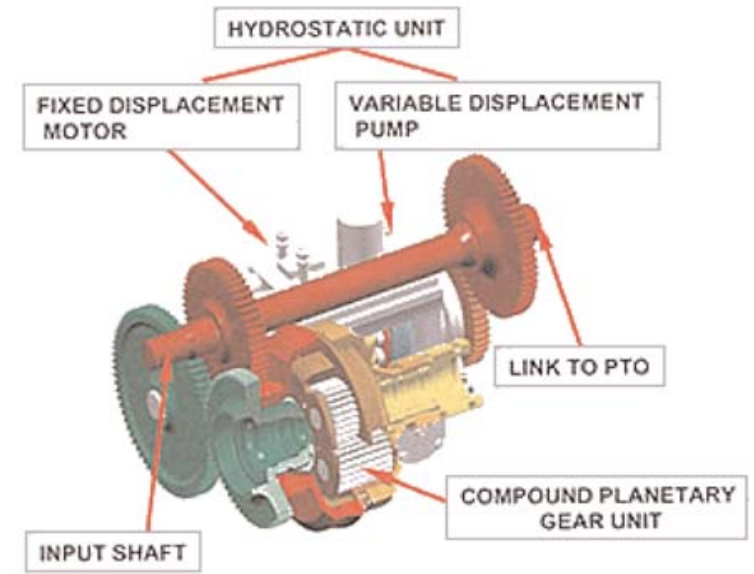

Fig. 7: Steyr CVT gearbox - parts and power split figuration
Figure 8 shows three clearly defined modes in the compound planetary gear. The internal gear depicted in red supplies the mechanical portion of the power transmission, is directly driven by the engine and thus always rotates in the same direction according to the engine speed.

The sun gear shown in green is driven by the hydrostatic motor and transmits the hydrostatic power.

\section{Compound planetary gear}

This unit consists of a 5-shaft planetary gear with two input shafts and three output shafts in which the actual superposition of the mechanical and hydrostatic power takes place.

\section{Mechanical 4-range transmission}

Planetary units in which 4 speed ranges are attained are connected to the compound planetary gear. The changeover between the individual speed ranges is carried out through overlap closing of special claw clutches at synchronous speeds without tractive force interruption. A planetary unit with direct link in forward travel and reversal of rotational direction in reverse travel is connected to the above.

Transmission and vehicle electronics

Special electronics enable control and regulation of transmission as well as interplay between the individual components. The mechanical power at the internal gear and the hydrostatic power at the sun gear of the compound planetary gear together provide the appropriate output in the respective speed ranges.

Through the superposition of the two input speeds (mechanical and hydrostatic) it is possible to achieve variable output speeds at a constant engine speed. In this way the travelling speed of 0 to $50 \mathrm{~km} / \mathrm{h}$ can be achieved forwards and backwards with continuously variable control and without tractive force interruption.
The speed and rotational direction of the sun gear can be varied by adjusting the inclined plate at the hydrostatic pump from the maximum speed in the opposite direction (mode 1), via stop (mode 2) to synchronous operation (mode 3 ) with the internal gear.

The respective output, which is now transmitted to the mechanical 4-range gear, results from the sum of sun gear and internal gear.

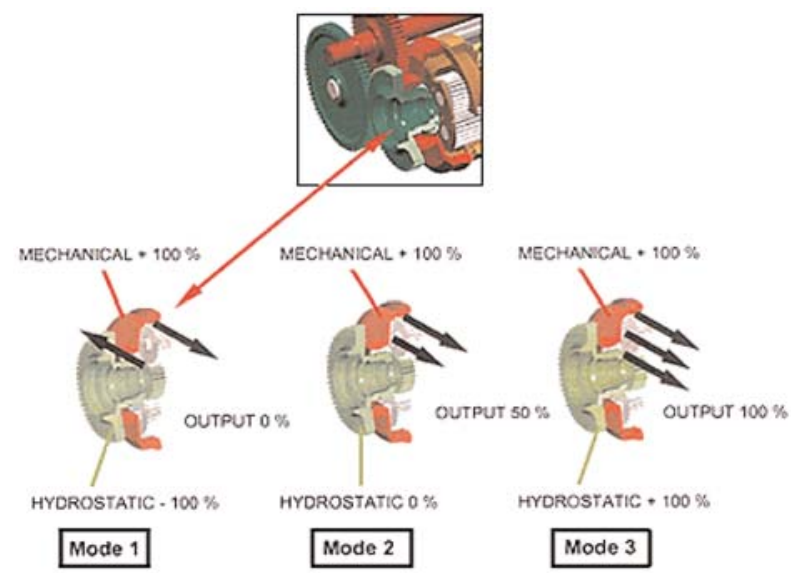

Fig. 8: Three speed modes of Steyr CVT 


\section{Fendt-Vario-Gearbox}

The engine output is directed to a planetary drive via a torsional vibration damper. Power is directed to the hydrostatic branch via the ring gear, and to the mechanical branch via the sun wheel. Both power trains are subsequently reunited at a collecting shaft with direct connection to the rear axle.

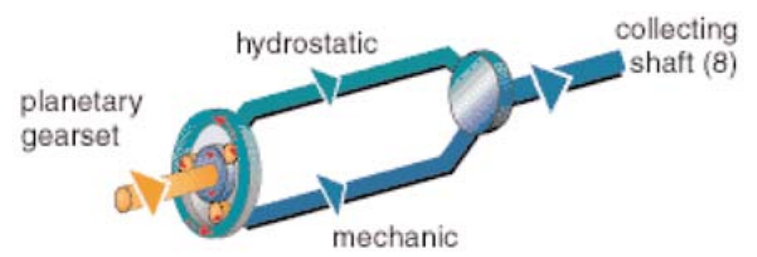

Fig. 9: Power split in Fendt-Vario gearbox

\section{Hydraulic drive unit}

The hydraulic branch consists of a top-efficiency variable pump, which drives two adjustable hydraulic motors on a common shaft. Pump and hydraulic motors are controlled in unison and have a particularly wide swing angle of $45^{\circ}$, which creates max. efficiency - a big advantage.

\section{Mechanical drive unit}

In the mechanical branch, which consists of planetary gears and range control, the residual torque is transferred via geared wheels to the collecting shaft where the two drive trains are combined.

\section{Power splitting}

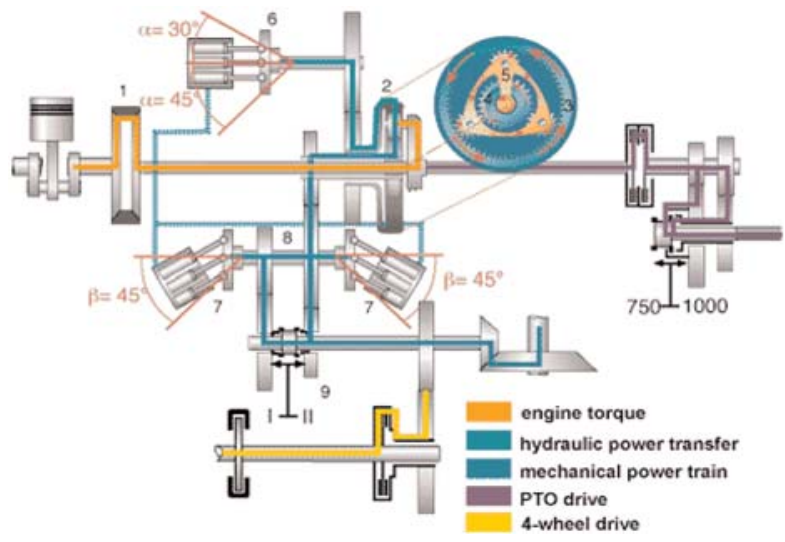

Fig. 10: Layout of Fendt-Vario with the power split representation: 1 torsional vibration damper, 2 planetary gear set, ring gear, 4 sun wheel, 5 planet carrier, 6 hydraulic motor, 7 hydraulic pump (400/700 Vario with own hydraulic motor), 8 collecting shaft, 9 travel range selector

\section{Conclusion}

The above named and listed solutions of hydromechanical transmissions with hydrostatic units show the potential of this transmission type. There are many useful properties that improve vehicle drive comfort (driveability), safety and fuel consumption. The result is that these transmission concepts designed with accent to required specific parameters achievement can also be used in other vehicles, not only in agricultural, defence and special ones. That is one of the main ideas in development of differential hydromechanical transmission with power split and hydrostatic units assigned for buses.

\section{References}

[1] http:/www.deutz-fahr.de

[2] http://www.silvatechgroup.com

[3] http:/www.torvec.com

[4] http://www.bonhillmarketing.co.uk/cvt.htm

[5] http:/www.fendt.com

[6] MÁLIK, L., KUČERA, L.: Mechanic, hydraulic and hydromechanical transmissions (in Slovak), EDIS - publisher of ŽU, Žilina, 1999.

[7] MÁLIK, L., ŠOŠKA, M.: Hydrostatic-mechanic power transmission (in Slovak). EDIS - publisher of ŽU, Žilina, 2002.

[8] MIKLUSAK, J: Stress analysis of gear box size A, Final report, 05/2004-AUT

[9] LOOMAN, J.: Gearboxes. Basics, designs, vehicle applications (in German). Springer - publishing, Berlin, Heidelberg, 1996.

[10] PODHORSKÝ, J., HRČEK, S.: New approaches and technologies in machine elements design (in Slovak). In: 45-th international machine elements and mechanisms departments conference, september 2004, Blansko, Czech Republic. ISBN 80-214-2702-7

[11] United States Patent Nr. 5186692, Hydromechanical orbital transmission

[12] United States Patent Nr. 5513553, Hydraulic machine with gear-mounted swash-plate

[13] PODHORSKÝ, J.: Expert system for design support, G.E.P. Miskolc, 1994

[14] PODHORSKÝ, J.: Information in design process and its processing (in Slovak), 1-st scientific PhD-student conferrence, Košice, 1995

[15] MIKLUŠÁK, J.: Use of modern computation methods by spur gearing analysis (in Slovak), 45-th international machine elements and mechanisms departments conference, Blansko 2004 